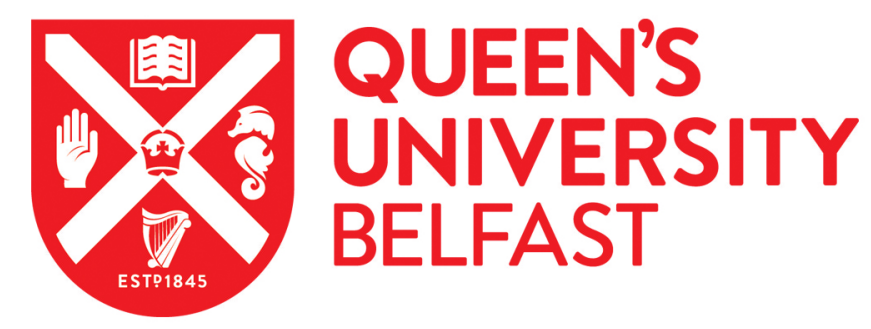

\title{
Diagnostic accuracy of haptoglobin within ovarian cyst fluid as a potential point-of-care test for epithelial ovarian cancer: an observational study
}

Mahyuddin, A. P., Liu, L., Zhao, C., Kothandaraman, N., Salto-Tellez, M., Pang, B., Lim, DGS., Annalamai, L., Chan, J. K. Y., Lim, T., Biswas, A., Rice, G., Razvi, K., \& Choolani, M. (2017). Diagnostic accuracy of haptoglobin within ovarian cyst fluid as a potential point-of-care test for epithelial ovarian cancer: an observational study. BJOG: An International Journal of Obstetrics and Gynaecology. https://doi.org/10.1111/1471-0528.14835

Published in:

BJOG: An International Journal of Obstetrics and Gynaecology

Document Version:

Peer reviewed version

Queen's University Belfast - Research Portal:

Link to publication record in Queen's University Belfast Research Portal

Publisher rights

(C) 2017 Royal College of Obstetricians and Gynaecologists. This work is made available online in accordance with the publisher's policies. Please refer to any applicable terms of use of the publisher.

\section{General rights}

Copyright for the publications made accessible via the Queen's University Belfast Research Portal is retained by the author(s) and / or other copyright owners and it is a condition of accessing these publications that users recognise and abide by the legal requirements associated with these rights.

\section{Take down policy}

The Research Portal is Queen's institutional repository that provides access to Queen's research output. Every effort has been made to ensure that content in the Research Portal does not infringe any person's rights, or applicable UK laws. If you discover content in the Research Portal that you believe breaches copyright or violates any law, please contact openaccess@qub.ac.uk. 
Article Type: Main Research Article

The diagnostic accuracy of haptoglobin within ovarian cyst fluid as a potential point-of-care test for epithelial ovarian cancer: an observational study

Aniza P Mahyuddin*, Lin Liu*, Chanqing Zhao, Kothandaraman Narasimhan, Manuel Salto-Tellez, Brendon Nghee Kheem Pang, Diana Gkeok Stzuan Lim, Loganath Annalamai, Jerry K Y Chan, Timothy Yong Kuei Lim, Arijit Biswas, Gregory Rice, Khalil Razvi", Mahesh Choolani\#.

Aniza P Mahyuddin

Department of Obstetrics \& Gynaecology,

National University of Singapore,

NUHS Tower Block, Level 12,

1E Kent Ridge Road,

Singapore 119228.

E-mail: obgapm@nus.edu.sg

Lin Liu

Murdoch Childrens Research Institute, 3rd Floor South Building,

Royal Children's Hospital

Flemington Road, Parkville, Victoria 3052 Australia.

E-mail: lin.liu@mcri.edu.au

Changqing Zhao

Boehringer Ingelheim (S) Pte Ltd,

37-00, The Concourse,

Singapore.

E-mail: zhaoosme@gmail.com

Narasimhan Kothandaraman

Department of Obstetrics \& Gynaecology,

National University of Singapore,

NUHS Tower Block, Level 12,

1E Kent Ridge Road,

This article has been accepted for publication and undergone full peer review but has not been through the copyediting, typesetting, pagination and proofreading process, which may lead to differences between this version and the Version of Record. Please cite this article as doi: $10.1111 / 1471-0528.14835$

This article is protected by copyright. All rights reserved. 
Singapore 119228.

E-mail: obgkn@yahoo.com

Manuel Salto-Tellez

Centre for Cancer Research and Cell Biology,

Room 01.003, CCRCB Block 5 MBC Site,

Queen's University, 97 Lisburn Road,

Belfast BT9 7AE, Northern Ireland,

United Kingdom.

Email: m.salto-tellez@qub.ac.uk

Brendon Nghee Kheem Pang

Department of Pathology, National University Hospital, 5, Lower Kent Ridge Road, 1 Main Building, Level 3, Singapore 119074.

Email: brendan_nk_pang@nuhs.edu.sg

\section{Diana Gkeok Stzuan Lim}

Department of Pathology, National University Hospital, 5, Lower Kent Ridge Road, 1 Main Building, Level 3, Singapore 119074.

Email: diana_gz_lim@nuhs.edu.sg

Loganath Annalamai

Department of Obstetrics \& Gynaecology, National University of Singapore, NUHS Tower Block, Level 12, 1E Kent Ridge Road, Singapore 119228.

E-mail: Retired. No contact details.

This article is protected by copyright. All rights reserved. 
Jerry KY Chan

Department of Reproductive Medicine,

KK Women's and Children's Hospital,

100 Bukit Timah Road,

Singapore 229899.

E-mail: jerrychan@duke-nus.edu.sg

Timothy Yong Kuei Lim

Department of Gynaecological Oncology,

KK Women's and Children's Hospital,

100 Bukit Timah Road,

Singapore 229899.

E-mail: timothy.lim.yk@kkh.com.sg

Arijit Biswas

Department of Obstetrics \& Gynaecology,

National University of Singapore,

NUHS Tower Block, Level 12,

1E Kent Ridge Road,

Singapore 119228.

E-mail: arijit_biswas@nuhs.edu.sg

Gregory Rice

University of Queensland Centre for Clinical Research,

Building 71/918,

Royal Brisbane \& Women's Hospital Campus,

The University of Queensland, Herston, QLD, 4029 Australia.

E-mail: g.rice@uq.edu.au

Khalil Razvi

Department of Obstetrics \& Gynaecology,

Southend University Hospital NHS Foundation Trust,

Westcliff-on-Sea, England, SSO ORY.

E-mail: khalil.razvi@southend.nhs.uk

Mahesh Choolani,

Department of Obstetrics \& Gynaecology,

National University of Singapore,

NUHS Tower Block, Level 12,

1E Kent Ridge Road,

Singapore 119228.

E-mail: obgmac@nus.edu.sg

Correspondence:

Mahesh Choolani,

Department of Obstetrics \& Gynaecology,

National University of Singapore,

This article is protected by copyright. All rights reserved. 
NUHS Tower Block, Level 12, 1E Kent Ridge Road,

Singapore 119228.

E-mail: obgmac@ nus.edu.sg

Tel: +65 67722672 Fax: +65 67794753

*Aniza P Mahyuddin and Lin Liu are joint first authors and contributed equally to this study.

\# Khalil Razvi and Mahesh Choolani are joint last authors.

Running title: Haptoglobin: point-of-care diagnostics for ovarian cancer

\section{ABSTRACT}

Objective: To investigate haptoglobin within ovarian cyst fluid (OCF) as a diagnostic biomarker for epithelial ovarian cancer (EOC) and develop an in vitro diagnostic point-ofcare device test (IVDPCT) for use in the operating theatre.

Design: Retrospective and prospective cohort study

Setting: South-East-Asia

Population: Women with suspicious ovarian cysts

Methods: Proteomic, immunohistochemical and ELISA methods measured haptoglobin in OCF to differentiate benign and EOCs. Diagnostic performance of haptoglobin was compared to CA125, Risk Malignancy Indices (RMI) and frozen section. Blinded validation of the IVDPCT was performed.

Main outcome measures: Prediction of malignancy

Results: In patients with benign cysts $(n=87)$ haptoglobin concentration measured by ELISA was $0.70 \pm 0.09 \mathrm{mg} / \mathrm{ml}$; early stage-EOC $(\mathrm{n}=17)$ was $6.22 \pm 0.53 \mathrm{mg} / \mathrm{ml}$; and late stage-EOC $(\mathrm{n}=20)$ was $6 \cdot 57 \pm 0.65 \mathrm{mg} / \mathrm{ml}$. Haptoglobin in EOCs was significantly higher than benign

This article is protected by copyright. All rights reserved. 
cysts $(P<0.0001)$. Haptoglobin using rapid colorimetric assay $(R C A)$ on a training set had sensitivity of $97.3 \%$ and specificity $92.0 \%$, comparable to ELISA and frozen sections. The haptoglobin AUROC curve was $0.999(95 \% \mathrm{Cl} 0.997-1.000)$ compared to $0.895(95 \% \mathrm{Cl}$ $0.814-0.977, P<0.05)$ for $C A 125$. Haptoglobin performed significantly better than all the RMls $(P<0.01)$. Blinded validation studies showed a minor drop in average diagnostic performance (sensitivity $85.2 \%$ and specificity $90.5 \%$ ) compared to training set. However, when compared to frozen section, haptoglobin was no worse in diagnostic accuracy for malignancy.

Conclusion: Haptoglobin was identified as a biomarker for the detection of EOC with potential as a point-of-care diagnostic tool.

Funding: This work was supported by the NUHS Cross Department Collaborative Grant, National Healthcare Group Small Innovative Grant, National Medical Research Council Clinician Scientists Award (CSA/007/2009, CSA/043/2012), SPRING, Singapore (Grant no: TI/TECS/POV/11/15) and National University of Singapore.

Keywords: epithelial ovarian cancer, in vitro diagnostic, biomarker, haptoglobin, point-ofcare, frozen section

Tweetable abstract: Haptoglobin within ovarian cyst fluid: a biomarker for epithelial ovarian cancer and point-of-care diagnostics

This article is protected by copyright. All rights reserved. 


\section{INTRODUCTION}

Epithelial ovarian cancer (EOC) is a disease with poor prognosis. Lifetime risk of developing EOC is $1.4 \%$, and worldwide 239,000 new cases are diagnosed annually. ${ }^{1}$ Two key factors that could improve survival in EOC are early diagnosis and appropriate primary surgery. ${ }^{2}$ Most patients are diagnosed at late stage (LSEOC), when the tumours respond poorly to therapy and have metastasised. ${ }^{3}$ Consequently, five-year survival rates are only $40 \%{ }^{4}$ In contrast, patients diagnosed with early-stage EOC (ES-EOC) have 5-year survival rates $>90 \%{ }^{5}$ There have been attempts to define symptoms that warrant earlier investigation, however, EOC symptom-complexes have low positive-predictive values (PPV) for ES-EOC ${ }^{6}$, and one in six ES-EOC patients are asymptomatic. ${ }^{7}$ No clinically-proven effective screening exists. ${ }^{8}$ There may be a role for a multimodal screening strategy $y^{4,9}$ however, the value of screening in lowering mortality may only be realised after protracted close surveillance. $^{4}$

Benign ovarian cysts are common ${ }^{10}$ and the relative preponderance of cancers versus benign cysts vary. $4,11,12$ The natural history of cysts remains poorly understood. ${ }^{9,13}$ Laparoscopy or laparotomy is the standard surgical approach for benign ovarian masses, ${ }^{8}$ but in up to $14 \%$, an unexpected malignancy is encountered. ${ }^{13}$ Preoperative prediction of the malignant potential remains challenging in early stage disease. This is especially true for ovarian masses identified in premenopausal women, and in South-East Asian countries where the

incidence of EOC rises in the thirties..$^{8,14-16}$ Intraoperative frozen section (FS) has been proposed to prevent delay in primary surgery, ${ }^{17}$ but suffers from several 
limitations such as wide variation in accuracy due to large size of cysts, sampling error, and limitation of available staining methods owing to time constraints ${ }^{18,19}$

Our pre-clinical exploratory proteomic studies demonstrated the presence of haptoglobin within the OCF which was able to differentiate between benign ovarian tumours, borderline and EOC (detailed in results and Appendix S1). As an acute phase reactant protein, serum haptoglobin concentrations rise in many cancers, but with poor sensitivities and specificities. In contrast, we showed through tissue microarray studies that haptoglobin within OCF accurately reflects the benign and malignant nature of the ovarian cystic masses since it is produced and concentrated locally within the cancer (detailed in results).

We hypothesised that haptoglobin may be of potential use as an in vitro diagnostic tool with the development and validation of a clinical assay using retrospective and prospective clinical samples.

\section{MATERIALS AND METHODS}

\section{Subject recruitment and sample collection}

We recruited 324 patients (Fig. 1A), between the ages of 11-74 years between December 2003 and March 2014 undergoing either laparoscopy or laparotomy for clinically suspicious tumours of the ovary at our local academic medical centre (LMC) and from five hospitals in Indonesia and Vietnam (regional medical centres, RMCs).

Our local academic medical centre recruited 284 patients (172 benign, 30 borderline and 82 malignant tumours), a combination of retrospective and prospective cohorts. In our retrospective cohort, we collected and archived ovarian cyst fluid from 184 patients. The

This article is protected by copyright. All rights reserved. 
histopathology diagnoses (frozen section, when conducted, and paraffin) for the 184 samples were known during selection for the type(s) of analysis that were performed. Retrospective sampling was performed to facilitate batch testing in laboratory investigations (preclinical and assay development phase). Prospective consecutive sampling was performed in 100 patients and analysed without any prior knowledge of the histopathology diagnosis (prospective validation phase). The RMC recruited 40 patients, and these samples were combined with our local retrospective cohort (31 benign tumours and 9 malignant tumours). In aggregate, they represented $17.9 \%$ of the whole retrospective cohort used.

The National Healthcare Group Domain Specific Review Board approved local collection and use of patient samples, and the local ethics committee at each regional centre gave corresponding approval. All patients gave written informed consent. All tumours were defined by histopathological diagnoses (reference standard) and staging was according to the International Federation of Gynecology and Obstetrics (FIGO) staging for ovarian cancer. ${ }^{20}$ Ovarian dermoid cysts, endometriotic cysts, pelvic inflammatory disease, tuboovarian abscesses, solid and frank malignant tumours were excluded from this study.

Ovarian cyst fluid samples were collected either at laparoscopy or laparotomy without spillage into the abdominal cavity. At laparotomy, the intact cyst was removed from the abdominal cavity followed by immediate aspiration of cyst contents via a syringe. At laparoscopy, the cyst was contained within an endobag and aspiration of the cyst was performed either from the endobag before or after being removed from the abdominal cavity. OCF that were heavily contaminated with blood were excluded as they contain haptoglobin and haemoglobin, which would interfere with our haptoglobin-based test. Retrospective samples were transported on ice to the laboratory, centrifuged at 2,000 $\mathrm{xg}$ for $10 \mathrm{~min}$ at $4^{\circ} \mathrm{C}$ and the supernatant stored in $-80^{\circ} \mathrm{C}$ until analysis. Prospective samples are kept on ice and analysed immediately, and not exceeding 4 hours post-cyst aspiration.

This article is protected by copyright. All rights reserved. 
Measurement of haptoglobin concentrations by ELISA and rapid colorimetric assay (RCA) on retrospective samples

The OCF haptoglobin concentrations were measured in benign tumours, and in ES- and LSEOCs using ELISA (Appendix S1) on 144 retrospective OCF samples (Fig. 1A). Histopathological classifications of all tumours (reference standard) and FIGO stages of malignant cases are detailed in Table S1 and S2. We used an RCA, and semi-quantitatively measured haptoglobin concentrations on the same retrospective cohort (Appendix S1). A receiver operating characteristic (ROC) curve was used to obtain haptoglobin cut-off concentrations (data not shown).

\section{Comparing OCF haptoglobin with CA125 and Risk of Malignancy Indices (RMIs) for prediction of malignancy}

Preoperative ultrasound reports and CA125 levels of patients recruited from LMC (Table S3) were obtained and evaluated for the risk of ovarian cancer by calculating three RMIs (RMI $1^{21}, \mathrm{RMI} 2^{22}$ and, RMI $3^{23}$; Appendix S1).

\section{Validation of OCF haptoglobin in blinded retrospective and prospective real-time samples}

We performed validation studies on 150 OCF samples (Fig. $1 \mathrm{~A}, \mathrm{n}=50$ retrospective and $\mathrm{n}=100$ prospective) in 96-well plate format (index test) (RCA) and IVDPCT format (index test) (RCA in IVDPCT; Development of IVDPCT- Appendix S1, Fig. S3) both in the laboratory and in the operating theatre (Appendix S1). The reference/gold standard for diagnosis of all tumours was tissue histopathology. Independent testers performed the index tests in the laboratory and operating theatre. The IVDPCT testers received training on IVDPCT use. Testers watched a training video of IVDPCT use followed by a live 
demostration of the IVDPCT. Next, the testers performed practicals using the IVPCT with known haptoglobin controls.

\section{Statistical analysis}

We tested data for normality with D'Agostino's $K^{2}$ test, and evaluated statistical significance with Student $t$ test (two-tailed) for comparison of age and peak intensity; Mann-Whitney $U$ test (two-tailed) for comparison of serum CA125 level, tissue expression of haptoglobin, and OCF haptoglobin concentration; and Fisher's exact test (two-tailed) or Pearson's chi-square test for comparison of the proportions of patients present with each ultrasound feature or score between benign and malignant EOCs. We used ROC curves to assess the performance of biomarkers and evaluated the statistical significance for the comparison of two areas under the curve. ${ }^{24}$ We used nonparametric Spearman and Bland-Altman for RCA and IVDPCT correlation tests. All statistical analyses were performed using GraphPad Prism 5.03 (GraphPad Software, La Jolla, CA, USA) and MedCalc v11.2.1.0 (MedCalc Software bvba, Mariakerke, Belgium). We expressed data as mean \pm S.E.M. and considered results statistically significant at $P<0.05$.

\section{RESULTS}

The results are presented in three phases: Preclinical Exploratory, Clinical Assay Development, and Prospective Validation studies.

Preclinical Exploratory phase: we present results of haptoglobin, a potential biomarker within OCF, identified through proteomics (mass spectrometry, SDSPAGE, SELDI western blot) and immunocytochemical (tissue microarray) methods.

This article is protected by copyright. All rights reserved. 
We analysed retrospective OCF (Fig. 1A) from benign ovarian tumours, ES-EOCs and LS-EOCs with SELDI-TOF/MS in mass ranges 7-60 kDa and identified a highintensity discriminatory peak at $17.5 \mathrm{kDa}$ that varied in proportion according to the extent of malignancy. It was present in 9/10 LS-EOCs, but absent/present at very low intensities in benign tumours. In early-stage disease, this peak was intermediate between benign and late-stage disease (Fig. S1A). Haptoglobin identity was confirmed by SDS-PAGE, peptide sequence matching, SELDI and western blot (Appendix S1; Fig. S1B-F; S2A,B).

Using immunohistochemistry on tissue microarray (TMA) slides, we observed strong expression within the epithelial lining cells of EOC and absent/weak expression of haptoglobin in the epithelial linings of normal ovaries and benign ovarian cysts (Fig. $\mathrm{S} 2 \mathrm{C})$. These images were converted to grey-scale luminosity grading. Here we showed that cancerous cells had significantly higher levels of haptoglobin expression than seen in benign tumour cells $(P<0.0001)$ (Fig. S2D), and borderline cells have intermediate staining.

Clinical Assay Development phase: we present ELISA (quantitative) and rapid colorimetric assay (semi-quantitative) measurements of haptoglobin between benign, borderline, ES- and LS-EOCs. Result of operating characteristics of haptoglobin versus CA125 and RMI's is shown. Results of assay optimisation, observer bias study and reproducibility in 96-well plate and IVDPCT are presented.

This article is protected by copyright. All rights reserved. 


\section{Detection of OCF haptoglobin concentration by ELISA and RCA.}

The OCF haptoglobin concentration detected by ELISA in women with ES- or LS-EOC $(6.22 \pm 0.53 \mathrm{mg} / \mathrm{ml}$ and $6.57 \pm 0.65 \mathrm{mg} / \mathrm{ml}$, respectively, $P>0.05)$ was significantly higher compared to that in women with benign tumours $(0.70 \pm 0.09 \mathrm{mg} / \mathrm{ml})(P<0.0001)$, although there was no significant difference in haptoglobin concentrations between ES-EOCs and LSEOCs (Fig. 1B). Amongst the women diagnosed with ES-EOC, five had serous carcinoma subtype (three low/intermediate-grade and two high-grade serous carcinoma (HGSC)). In all these samples, haptoglobin concentrations (range 3.9-7.3 mg/ml) were higher than the cutoff value $(2.85 \mathrm{mg} / \mathrm{ml})$. The accuracy of RCA (at cut-off $0.5 \mathrm{mg} / \mathrm{ml}$ ) was similar to that of ELISA (at cut-off $2.85 \mathrm{mg} / \mathrm{ml}$ ) (Table 1) as determined using retrospective OCF samples ( $n=124$; Fig. 1A, Table S1). Using an ELISA-based assay, haptoglobin has an overall sensitivity of $97.3 \%$ and NPV of $98.8 \%$ (Table 1). When considering only retrospective regional medical centre samples, in resource-challenged countries, the sensitivity and NPV are $88.9 \%$ and $96.9 \%$, respectively. Using an RCA where the results could be ready in five minutes inside the operating theatre, the overall sensitivity and NPV were $97.3 \%$ and $98.8 \%$, respectively (Table 1). Figure S4 demonstrates the appearance of the RCA in a 96-well plate.

Of the 84 retrospective local academic medical centre cases, 33 women had FSs performed, with 16 benign and 17 cancerous cases as confirmed by histopathology. The overall accuracy in determination of the status of malignancy was $97.0 \%$ for cyst fluid haptoglobin determined by ELISA, $93.9 \%$ by RCA, and $90.9 \%$ for FS (Table 2A). Three cases $(9.1 \%)$ had FS diagnosis discordant with the histopathology. There was one ES-EOC that FS misdiagnosed as benign (false negative), and two benign tumours misdiagnosed as borderline tumours (false positives). In contrast, in one case (3.0\%) OCF haptoglobin measurements by ELISA and in two cases by RCA (6.1\%) were discordant with histopathology. All discordant cases were benign tumours being over-diagnosed. Overall,

This article is protected by copyright. All rights reserved. 
sensitivity, specificity, PPV and NPV of both methods of detecting OCF haptoglobin were similar to FS (Table 2A).

OCF haptoglobin is more accurate than CA125 or RMIs.

$\mathrm{RMI}$ is used frequently in the preoperative triage of patients with ovarian cysts. Menopause status is one key discriminant used in this risk calculation. In the Caucasian population, $>80 \%$ of EOC patients are postmenopausal. In our local academic medical centre cohort, the mean ages for the benign and malignant groups were $39.6 \pm 13.9$ and $51.5 \pm 10.0$ respectively $(P<0.0001)$, but $50 \%(14 / 28)$ of patients with cancer were premenopausal, which lead to lower RMI scores (Table S3). Another key component of the RMI is the CA125 concentration. In our cohort, ten percent of women with benign cysts had elevated CA125 concentrations and $14.3 \%$ of patients with malignant disease had a CA125<35 U/ml. Using a ROC curve analysis (Fig. 1C), we show that haptoglobin had superior diagnostic efficiency (AUC 0.999, 95\%Cl 0.997-1.000) compared with CA125 (AUC 0.895, 95\%Cl 0.814-0.977; percentage $\Delta=10.4 \% ; P=0.013)$. Three versions of the RMI have been used, which are similar in principle (menopausal status, ultrasound features and CA125 concentrations), but differ in the weights of each element: RMI $1^{21}$, RMI $2^{22}$ and, RMI $3^{23}$. Here too, haptoglobin out-performed all three RMIs (Fig. 1C).

Assay optimisation, observer bias study and reproducibility in 96-well plate and IVDPCT

This article is protected by copyright. All rights reserved. 
In the laboratory, we tested RCA in 96-well plates (Fig. S4) and IVDPCT formats (Fig. S3) using 50 retrospective samples (Fig. 1A, Table S5) where histopathology diagnoses were blinded to the testers (Appendix S1). The IVDPCT was in agreement with that of 96 -well plate, as indicated by absorbance (630 nm) (Spearman's slope $=1.25, R^{2}=0.961$; Bland-Altman (BA) bias= -0.08 (Fig. S5A,B)). There was no significant difference between the mean absorbance for the 96-well and for the IVDPCT ( $P>0.05 ;$ Table S4). There was no interobserver difference in the discrimination of visual colour appearance between the 96-well and IVDPCT (BA bias=0; Fig. $\mathrm{S} 5 \mathrm{C}$ ) and good agreement of visual calls compared to histopathology diagnoses (BA bias=0.01; Fig. S5D) with sensitivity of $100 \%$, specificity $96 \cdot 8 \%$, PPV 95\%, and NPV 100\% (Table 3).

Prospective Validation phase: we present sensitivity, specificity, PPV and NPV results of 100 prospective blinded OCF sample assayed in the laboratory and operating theatre.

Fifty consecutive prospective blinded samples were collected at surgery for ovarian cyst and tested in the laboratory using the RCA (index test) (Fig. 1A) and compared to histopathology diagnosis (reference standard; Table S5). We observed sensitivity of $85.7 \%(95 \% \mathrm{Cl} 62 \cdot 6-96 \cdot 2 \%)$, specificity of $89 \cdot 7 \%(95 \% \mathrm{Cl} 71 \cdot 5-97 \cdot 3 \%)$, PPV of $85 \cdot 7 \%(95 \% \mathrm{Cl} 62 \cdot 6-96 \cdot 2 \%)$, and NPV of $89 \cdot 7 \%(95 \% \mathrm{Cl} 71 \cdot 5-97 \cdot 3 \%)$ (Table 3).

We followed this up with a prospective blinded study of the IVDPCT (index test) with 50 OCF consecutively sampled and tested real-time (Fig. 1A) in the operation theatre with the IVDPCT tester blinded to the type of surgery performed and diagnosis. We recorded visual calls from the IVDPCT and compared to FS and 
histopathology (reference standard obtained 1-2 weeks post-surgery; Table S5). The IVDPCT had sensitivity of $70 \%(95 \% \mathrm{Cl}$ : $35 \cdot 4-91 \cdot 9 \%)$, specificity of $85 \%(95 \% \mathrm{Cl}$ : $69 \cdot 5-93 \cdot 8 \%)$, PPV of $53 \cdot 8 \%$ (95\% Cl: $26 \cdot 1-79 \cdot 6 \%)$, and NPV of $91 \cdot 9 \%(95 \% \mathrm{Cl}: 77-$ 97.9\%)(Table 3). Of the 50 IVDPCT cases tested in theatre, 26 had FSs performed, with 22 benign and 4 cancerous cases as confirmed by histopathology. The overall accuracy in determination of the status of malignancy was $92.3 \%$ for IVDPCT compared to $88 \%$ for FS (Table 2B). Three cases $(11.5 \%$ ) had FS diagnosis incompatible with histopathology and one FS without a diagnosis due to technical difficulties during tissue cryosectioning (IVDPCT result matched histopathology). Three benign tumours were misdiagnosed: one low-grade neoplasm and two borderline tumours (false positives). In contrast, two cases (7.7\%) by IVDPCT had OCF haptoglobin measurements discordant with histopathology. All discordant cases were benign tumours being over-diagnosed (false positives). Overall diagnostic performance was higher in IVDPCT when compared to FS (Table 2B).

\section{DISCUSSION}

\section{Main findings}

We demonstrated the presence of haptoglobin in OCF of benign, borderline and malignant EOCs. The concentration of haptoglobin was significantly raised in ES and LS-EOC compared to benign tumours. We also observed raised haptoglobin concentrations in OCF of low-volume HGSC's.

Semi-quantitative measurements of haptoglobin using a RCA in clinical assay development gave diagnostic accuracies similar to ELISA and frozen section. The haptoglobin AUROC curve was $0.999(95 \% \mathrm{Cl} 0.997-1.000)$ compared to 0.895 
$(95 \% \mathrm{Cl} 0.814-0.977, \mathrm{P}<0.05)$ for $\mathrm{CA} 125$. Haptoglobin performed significantly better than all the RMls $(P<0.01)$. We showed good correlation and between the RCA and IVDPCT and minimal intra- and inter-observer bias.

In our prospective validation study, the diagnostic accuracy of IVDPCT was marginally poorer compared to that of the assay development tests, but it does maintain accuracy which is comparable to FS.

\section{Strengths and limitations}

Several studies exploring OCF for biomarker analysis found it to have little use for discriminating between benign and malignant tumours. ${ }^{25,26}$ One study suggested that OCF contained tumour-specific biomarkers, ${ }^{25}$ but this study had several limitations. The putative biomarkers identified by protein profiling were not confirmed by analysis of the exact peptide sequence; none of the peaks were superior to CA125 used alone; and a 1:1 ratio of benign versus malignant samples were used leading to a discovery strategy that would yield low PPVs. ${ }^{27}$

We analysed haptoglobin concentrations in 324 OCF samples and haptoglobin is able to differentiate benign from malignant EOCs with high accuracy. Only haptoglobin within borderline ovarian tumour samples showed poorer diagnostic accuracy for malignancy when compared to FS, and haptoglobin's accuracy was only marginally better compared to CA125 or RMI1 (Table S2). A recent Cochrane review highlighted similar problems with the accuracy of frozen section in the diagnosis of borderline ovarian tumours. ${ }^{19}$ This validated our FS findings of poorer 
accuracy $(80 \%)$ in borderline ovarian tumours when compared to paraffin histopathology (Table S2).

Tissue microarray study of 141 ovarian tissue samples showed haptoglobin accumulation within ovarian cyst fluid is more reflective of the biological changes within the tumour microenvironment. Although the pathophysiology of haptoglobin overexpression within malignant cysts remains unclear, we showed specific overexpression within the epithelial lining cells of cancerous cysts (Fig. S2C). While some investigators have shown presence of haptoglobin-1 precursor (HAP1) within ovarian cancer cells, ${ }^{28}$ other acute phase reactants have also been reportedly raised in HGSC's. ${ }^{29}$

Unlike the RMIs, haptoglobin-based segregation for malignancy was independent of the patient's menopausal status. Here, haptoglobin performed significantly better when compared with either CA125 used alone, or as part of the RMls. This is because in the western hemisphere, EOC is a disease mainly in the postmenopausal women. ${ }^{21}$ In contrast; half of the women with EOC in our study were premenopausal. This is in keeping with national data from Singapore (National Cancer Registry), and with our own hospital data collected over three years, suggesting an earlier rise in the incidence of EOC locally and regionally. ${ }^{14-16}$ The sensitivity of RMI1 for adnexal masses in this local hospital cohort of Asian patients is only 54\%. Recent use of the IOTA risk prediction model has shown a higher accuracy than RMI in both pre- and post-menopausal women, but still does not remove the need for intraoperative diagnostics in evaluation of suspicious ovarian tumours. ${ }^{30}$ 
EOC prevalence in our study ranged between $20 \%$ and $42 \%$, which reflects clinical practice, as there are greater numbers of benign compared to malignant cases undergoing investigation. Even with the increased number of benign samples tested, haptoglobin gave high positive predictive values (PPV's) (range 83.7\% to 94.7\%) in all OCF samples. Typically, estimates of diagnostic performance in the validation samples are more realistic (and lower) than in the clinical assay development samples and this is seen in the lowered diagnostic performance of the validation samples. Due to the smaller sample size and lower prevalence of EOC, the confidence interval for the validation set is wider, compared to the assay development samples.

\section{Interpretation}

In our study, haptoglobin and FS seem to have comparable diagnostic accuracies. Sensitivity of FS varies between $65-97 \%$, with specificities of $97-100 \%$ according to a meta-analysis. ${ }^{18}$ Factors contributing to this wide variation in accuracy include large size of cysts, sampling error, and limitation of available staining methods owing to time constraints. ${ }^{18,19}$ The overall utility of FS is even worse because of additional logistical limitations, and it can create inefficiencies in operating room utilisation with surgeries pausing for $>30$ minutes, increasing patient morbidity. Haptoglobin however, has the additional benefit of being a rapid, easy, and cost-efficient diagnostic test to perform at the patient's point-of-care.

The IVDPCT is intended for use in women undergoing surgical investigation for a suspicious cystic mass, as a triage for FS, or even as a surrogate for FS in resourcechallenged countries where FS is not available. In a test with a high NPV, such as 
this, if the IVDPCT were negative, we could avoid FS and complete the surgery; a true positive test would require either a FS or involvement of gynaecologic oncologists if FS were not readily available. Initial surgery performed by a gynaecologic oncologist is associated with accurate staging, complete resection of disease and improved patient prognosis. ${ }^{31,32}$

\section{Conclusion and research recommendations}

The present study is the first demonstration of OCF haptoglobin as a highly discriminatory biomarker between benign and malignant EOCs. Larger prospective blinded clinical studies are required to determine the operating characteristics of the IVDPCT in a relevant population to determine detection and false negative rates. Larger trials are also needed in identifying malignant cases and selecting benign cases that would not require FS evaluation. Our data suggests the potential utility of OCF haptoglobin as an in vitro diagnostic point-ofcare tool with accuracy comparable to frozen section.

\section{Acknowledgements}

L.L received scholarship from the National University of Singapore and mentorship by Dr Loganath Annalamai. We thank Dr Stephen C.L. Koh and the Ovarian Cancer Network Group in Indonesia (Rumah Sakit Sanglah, Denpasar; Dr Mohammad Hoesin Hospital, Palembang; Rumah Sakit Umum Pusat Dr Sardjito, Yogyakarta;

Rumah Sakit Dr Cipto Mangunkusumo, Jakarta) and Vietnam (Tu Du Hospital, Ho Chi Minh City) for the collection of regional ovarian cyst fluid samples. The authors would like to thank Hock Leng Medtech Solutions and Innovation Exchange Pte Ltd for their assistance in the design and development of the point-of-care device.

This article is protected by copyright. All rights reserved. 


\section{Disclosure of interests}

The National University of Singapore (NUS) has licensed the patents out to INEX Innovations Exchange Pte Ltd, a local company spun out from the university by three of the authors - $A B, K R$ and $M C$. MC, holds shares in, and is a non-executive director of INEX Innovations Exchange Pte Ltd. KR and AB are shareholders of INEX Innovations Exchange Pte Ltd. All other authors declare no conflict of interest. The ICMJE disclosure forms are available as online supporting information.

\section{Contribution to authorship}

LL, APM and MC designed experiments, analysed data and wrote the manuscript. GR, KN, LA and CZ assisted with proteomic study. TLYK and JKYC contributed key reagents and advice. MST, DGSL and BNKP performed the tissue microarray study. $\mathrm{AB}, \mathrm{KR}$ and $\mathrm{MC}$ conceived and supervised the project. All authors provided critical comments and editorial changes.

\section{Ethics approval}

The National Healthcare Group Domain Specific Review Board, Singapore (D/00/856 - $8^{\text {th }}$ June 2000); DSRB2007/00240 - July 2007) approved local collection and use of patient samples, and the local ethics committee at each regional centre gave corresponding approval. All patients gave written informed consent.

\section{Funding}

This work was supported by the NUHS Cross Department Collaborative Grant, National Healthcare Group Small Innovative Grant, National Medical Research Council Clinician Scientists Award A/Prof Mahesh Choolani (CSA/007/2009) and 
A/Prof Jerry K.Y. Chan (CSA/043/2012) and SPRING, Singapore (Grant no: TI/TECS/POV/11/15). L.L received scholarship from the National University of Singapore.

\section{REFERENCES}

1. Ferlay J, Soerjomataram I, Dikshit R, Eser S, Mathers C, Rebelo M, et al. Cancer incidence and mortality worldwide: sources, methods and major patterns in GLOBOCAN 2012. Int J Cancer. 2015;136(5):E359-86.

2. Engelen MJ, Kos HE, Willemse PH, Aalders JG, de Vries EG, Schaapveld M, et al. Surgery by consultant gynecologic oncologists improves survival in patients with ovarian carcinoma. Cancer. 2006;106(3):589-98.

3. Lurie G, Thompson PJ, McDuffie KE, Carney ME, Goodman MT. Prediagnostic symptoms of ovarian carcinoma: a case-control study. Gynecologic Oncology. 2009;114(2):231-6.

4. Jacobs IJ, Menon U, Ryan A, Gentry-Maharaj A, Burnell M, Kalsi JK, et al. Ovarian cancer screening and mortality in the UK Collaborative Trial of Ovarian Cancer Screening (UKCTOCS): a randomised controlled trial. Lancet. 2015.

5. Howlader N., et al. SEER Cancer Statistics Review, 1975-2011, National Cancer Institute. Bethesda, MD, based on November 2013 SEER data submission, posted to the SEER web site, April 2014. Available at: http://seer.cancer.gov/csr/1975_2011/. Retrieved July 20, 2016.

This article is protected by copyright. All rights reserved. 
6. Rossing MA, Wicklund KG, Cushing-Haugen KL, Weiss NS. Predictive value of symptoms for early detection of ovarian cancer. Journal of the National Cancer Institute. 2010;102(4):222-9.

7. Nagle CM, Francis JE, Nelson AE, Zorbas H, Luxford K, de Fazio A, et al. Reducing time to diagnosis does not improve outcomes for women with symptomatic ovarian cancer: a report from the Australian Ovarian Cancer Study Group. Journal of Clinical Oncology : Official Journal of the American Society of Clinical Oncology. 2011;29(16):2253-8.

8. Greentop guideline No 62 RCOG/BSGE Joint Guideline I. Management of suspected ovarian masses in premenopausal women. November 2011. Available at: https://www.rcog.org.uk/globalassets/documents/guidelines/gtg_62.pdf.

Retrieved July 20, 2016.

9. Buys SS, Partridge E, Black A, Johnson CC, Lamerato L, Isaacs C, et al. Effect of screening on ovarian cancer mortality: the Prostate, Lung, Colorectal and Ovarian (PLCO) Cancer Screening Randomized Controlled Trial. JAMA. 2011;305(22):2295-303.

10. Shaaban A, Rezvani M. Ovarian cancer: detection and radiologic staging. Clinical Obstetrics and Gynecology. 2009;52(1):73-93.

11. Westhoff C, Clark CJ. Benign ovarian cysts in England and Wales and in the United States. British Journal of Obstetrics and Gynaecology. 1992;99(4):32932.

12. Crayford TJ, Campbell S, Bourne TH, Rawson HJ, Collins WP. Benign ovarian cysts and ovarian cancer: a cohort study with implications for screening. Lancet. 2000;355(9209):1060-3.

This article is protected by copyright. All rights reserved. 
13. Marana R, Muzii L, Ferrari S, Catalano GF, Zannoni G, Marana E. Management of adnexal cystic masses with unexpected intracystic vegetations detected during laparoscopy. Journal of Minimally Invasive Gynecology. 2005;12(6):502-7.

14. Ong C, Biswas A, Choolani M, Low JJ. Comparison of risk of malignancy indices in evaluating ovarian masses in a Southeast Asian population. Singapore Medical Journal. 2013;54(3):136-9.

15. Ministry of Health Singapore. National Registry of Diseases Office. Trends in Cancer Incidence in Singapore 2010-2014. Available at: https://www.nrdo.gov.sg/docs/librariesprovider3/default-documentlibrary/cancer-trends-report-2010---2014_web.pdf?sfvrsn=0. Retrieved 20 July, 2016.

16. National Cancer Registry. Ministry of Health, Malaysia. National Cancer Registry Report Malaysia Cancer Statistics - Data and Figure 2007. Available at: http://www.care.upm.edu.my/dokumen/13603_NCR2007.pdf Retrieved 20 July, 2016.

17. Chapron C, Dubuisson JB, Kadoch O, Capella-Allouc S, Vacher-Lavenu MC. Laparoscopic management of organic ovarian cysts: is there a place for frozen section diagnosis? Human reproduction. 1998;13(2):324-9.

18. Geomini PM, Zuurendonk LD, Bremer GL, de Graaff J, Kruitwagen RF, Mol BW. The impact of size of the adnexal mass on the accuracy of frozen section diagnosis. Gynecologic Oncology. 2005;99(2):362-6.

19. Ratnavelu ND, Brown AP, Mallett S, Scholten RJ, Patel A, Founta C, et al. Intraoperative frozen section analysis for the diagnosis of early stage ovarian 
cancer in suspicious pelvic masses. Cochrane Database Syst Rev. 2016;3:CD010360.

20. Prat J, Oncology FCoG. Staging classification for cancer of the ovary, fallopian tube, and peritoneum. Int J Gynaecol Obstet. 2014;124(1):1-5.

21. Jacobs I, Oram D, Fairbanks J, Turner J, Frost C, Grudzinskas JG. A risk of malignancy index incorporating CA 125, ultrasound and menopausal status for the accurate preoperative diagnosis of ovarian cancer. British Journal of Obstetrics and Gynaecology. 1990;97(10):922-9.

22. Tingulstad S, Hagen B, Skjeldestad FE, Onsrud M, Kiserud T, Halvorsen T, et al. Evaluation of a risk of malignancy index based on serum CA125, ultrasound findings and menopausal status in the pre-operative diagnosis of pelvic masses. British Journal of Obstetrics and Gynaecology. 1996;103(8):826-31 .

23. Tingulstad S, Hagen B, Skjeldestad FE, Halvorsen T, Nustad K, Onsrud M. The risk-of-malignancy index to evaluate potential ovarian cancers in local hospitals. Obstetrics and Gynecology. 1999;93(3):448-52.

24. Delong ER, Delong DM, Clarkepearson DI. Comparing the Areas under 2 or More Correlated Receiver Operating Characteristic Curves - a Nonparametric Approach. Biometrics. 1988;44(3):837-45.

25. Chudecka-Glaz A, Rzepka-Gorska I, Kosmowska B. Gonadotropin (LH, FSH) levels in serum and cyst fluid in epithelial tumours of the ovary. Archives of Gynecology and Obstetrics. 2004;270(3):151-6.

26. Kristjansdottir B, Partheen K, Fung ET, Marcickiewicz J, Yip C, Brannstrom M, et al. Ovarian cyst fluid is a rich proteome resource for detection of new tumour biomarkers. Clinical Proteomics. 2012;9(1):14. 
27. Elwood M. Proteomic patterns in serum and identification of ovarian cancer. Lancet. 2002;360(9327):170; author reply -1.

28. Ahmed N, Barker G, Oliva KT, Hoffmann P, Riley C, Reeve S, et al. Proteomic-based identification of haptoglobin-1 precursor as a novel circulating biomarker of ovarian cancer. British Journal of Cancer. 2004;91(1):129-40.

29. Yigit R, Massuger LF, Zusterzeel PL, Pots J, Figdor CG, Torensma R. Cytokine profiles in cyst fluids from ovarian tumours reflect immunosuppressive state of the tumour. Int $\mathrm{J}$ Gynecol Cancer. 2011;21(7):1241-7.

30. Testa A, Kaijser J, Wynants L, Fischerova D, Van Holsbeke C, Franchi D, et al. Strategies to diagnose ovarian cancer: new evidence from phase 3 of the multicentre international IOTA study. British Journal of Cancer. 2014;111(4):680-8.

31. National Institute for Health and Clinical Excellence (NICE) Clinical Guideline 122. Ovarian Cancer: The recognition and initial management of ovarian cancer. Issued 27 April 2011. Available at: http://www.nice.org.uk/guidance/cg122/resources/ovarian-cancer-recognitionand-initial-management-35109446543557. Retrieved July 20, 20

32. du Bois A, Reuss A, Pujade-Lauraine E, Harter P, Ray-Coquard I, Pfisterer J. Role of surgical outcome as prognostic factor in advanced epithelial ovarian cancer: a combined exploratory analysis of 3 prospectively randomized phase 3 multicentre trials: by the Arbeitsgemeinschaft Gynaekologische Onkologie Studiengruppe Ovarialkarzinom (AGO-OVAR) and the Groupe d'Investigateurs Nationaux Pour les Etudes des Cancers de l'Ovaire (GINECO). Cancer. 2009;115(6):1234-44. 
TABLES

Table 1 Clinical assay development: sensitivity, specificity, PPV and NPV of cyst fluid haptoglobin determined by ELISA and rapid colorimetric assay in the differential diagnosis of benign and malignant epithelial ovarian tumours in retrospective archived samples from 124 women.

\begin{tabular}{|c|c|c|c|c|c|c|}
\hline \multirow{6}{*}{$\begin{array}{l}\text { Test + } \\
\text { Test - } \\
\text { Total }\end{array}$} & \multicolumn{6}{|c|}{ Local academic medical centre, $\mathrm{N}=84$} \\
\hline & \multicolumn{3}{|c|}{ Haptoglobin by ELISA* } & \multicolumn{3}{|c|}{ Haptoglobin by rapid colorimetric assay ${ }^{\star \star}$} \\
\hline & $\mathrm{CA}$ & Non-CA & Total & $\mathrm{CA}$ & Non-CA & Total \\
\hline & 28 & 2 & 30 & 27 & 3 & 30 \\
\hline & 0 & 54 & 54 & 1 & 53 & 54 \\
\hline & 28 & 56 & 84 & 28 & 56 & 84 \\
\hline & Value & \multicolumn{2}{|c|}{ 95\% Confidence Interval } & Value & \multicolumn{2}{|c|}{$95 \%$ Confidence Interval } \\
\hline & & Lower & Upper & & Lower & Upper \\
\hline Sensitivity & 100 & $85 \cdot 0$ & 100 & $96 \cdot 4$ & $79 \cdot 8$ & $99 \cdot 8$ \\
\hline Specificity & $96 \cdot 4$ & $86 \cdot 6$ & $99 \cdot 4$ & $94 \cdot 6$ & $84 \cdot 2$ & $98 \cdot 6$ \\
\hline PPV & $93 \cdot 3$ & $76 \cdot 5$ & $98 \cdot 8$ & $90 \cdot 0$ & $72 \cdot 3$ & $97 \cdot 4$ \\
\hline \multirow[t]{4}{*}{ NPV } & 100 & $91 \cdot 7$ & 100 & $98 \cdot 1$ & $88 \cdot 8$ & $99 \cdot 9$ \\
\hline & \multicolumn{6}{|c|}{ Regional, $\mathrm{N}=40$} \\
\hline & \multicolumn{3}{|c|}{ Haptoglobin by ELISA* } & \multicolumn{3}{|c|}{ Haptoglobin by rapid colorimetric assay** } \\
\hline & CA & Non-CA & Total & $\mathrm{CA}$ & Non-CA & Total \\
\hline Test + & 8 & 0 & 8 & 9 & 4 & 13 \\
\hline Test - & 1 & 31 & 32 & 0 & 27 & 27 \\
\hline \multirow[t]{3}{*}{ Total } & 9 & 31 & 40 & 9 & 31 & 40 \\
\hline & Value & \multicolumn{2}{|c|}{$95 \%$ Confidence Interval } & Value & \multicolumn{2}{|c|}{$95 \%$ Confidence Interval } \\
\hline & & Lower & Upper & & Lower & Upper \\
\hline Sensitivity & $88 \cdot 9$ & $50 \cdot 7$ & $99 \cdot 4$ & 100 & $62 \cdot 9$ & 100 \\
\hline Specificity & 100 & $86 \cdot 3$ & 100 & $87 \cdot 1$ & $69 \cdot 2$ & $95 \cdot 8$ \\
\hline PPV & 100 & $59 \cdot 8$ & 100 & $69 \cdot 2$ & $38 \cdot 9$ & $89 \cdot 6$ \\
\hline \multirow[t]{4}{*}{ NPV } & $96 \cdot 9$ & $82 \cdot 0$ & $99 \cdot 8$ & 100 & $84 \cdot 5$ & 100 \\
\hline & \multicolumn{6}{|c|}{ Combined local and regional, $\mathrm{N}=124$} \\
\hline & \multicolumn{3}{|c|}{ Haptoglobin by ELISA* } & \multicolumn{3}{|c|}{ Haptoglobin by rapid colorimetric assay ${ }^{\star \star}$} \\
\hline & CA & Non-CA & Total & $\mathrm{CA}$ & Non-CA & Total \\
\hline Test + & 36 & 2 & 38 & 36 & 7 & 43 \\
\hline Test - & 1 & 85 & 86 & 1 & 80 & 81 \\
\hline \multirow[t]{3}{*}{ Total } & 37 & 87 & 124 & 37 & 87 & 124 \\
\hline & Value & \multicolumn{2}{|c|}{ 95\% Confidence Interval } & Value & \multicolumn{2}{|c|}{ 95\% Confidence Interval } \\
\hline & & Lower & Upper & & Lower & Upper \\
\hline Sensitivity & $97 \cdot 3$ & $84 \cdot 2$ & 99.9 & $97 \cdot 3$ & $84 \cdot 2$ & 99.9 \\
\hline Specificity & $97 \cdot 7$ & $91 \cdot 1$ & $99 \cdot 6$ & $92 \cdot 0$ & $83 \cdot 6$ & $96 \cdot 4$ \\
\hline PPV & $94 \cdot 7$ & $80 \cdot 9$ & $99 \cdot 1$ & 83.7 & $68 \cdot 7$ & $92 \cdot 7$ \\
\hline NPV & $98 \cdot 8$ & $92 \cdot 8$ & 99.9 & $98 \cdot 8$ & $92 \cdot 4$ & $99 \cdot 9$ \\
\hline
\end{tabular}

${ }^{*}$ Haptoglobin at cut-off $2.85 \mathrm{mg} / \mathrm{ml}$; ${ }^{* *}$ Haptoglobin at cut-off $0.5 \mathrm{mg} / \mathrm{ml}$. CA-Cancer; Non-CA NonCancer; PPV - positive predictive value; NPV - negative predictive value

This article is protected by copyright. All rights reserved. 
Table 2 Diagnostic accuracy of index test versus frozen section in clinic assay development and prospective validation phase. (A) Clinical assay development phase: ELISA, rapid colorimetric assay and frozen section compared to histology for the diagnosis of epithelial ovarian tumours in a subset of women $(n=33)(B)$ Prospective validation (in operating theatre): IVDPCT and frozen section compared to histology for the diagnosis of epithelial ovarian tumours in a subset of women $(n=26)$.

\begin{tabular}{|c|c|c|c|c|c|c|c|c|c|}
\hline \multirow[t]{2}{*}{ A. } & \multicolumn{3}{|c|}{ Haptoglobin by ELISA ${ }^{*}$} & \multicolumn{3}{|c|}{$\begin{array}{l}\text { Haptoglobin by rapid } \\
\text { colorimetric assav }\end{array}$} & \multicolumn{3}{|c|}{ Frozen section } \\
\hline & CA & $\begin{array}{l}\text { Non- } \\
\text { CA }\end{array}$ & Total & $\mathrm{CA}^{\mathrm{CO}}$ & $\begin{array}{l}\text { imetric as } \\
\text { Non-CA }\end{array}$ & $\begin{array}{l}\mathbf{y}^{\star \star} \\
\text { Total }\end{array}$ & CA & Non-CA & Total \\
\hline Test + & 17 & 1 & 18 & 17 & 2 & 19 & 16 & 2 & 18 \\
\hline Test - & 0 & 15 & 15 & 0 & 14 & 14 & 1 & 14 & 15 \\
\hline \multirow[t]{3}{*}{ Total } & 17 & 16 & 33 & 17 & 16 & 33 & 17 & 16 & 33 \\
\hline & $\begin{array}{l}\text { Value } \\
(\%)\end{array}$ & \multicolumn{2}{|c|}{$\begin{array}{l}\text { 95\% Confidence } \\
\text { Interval (\%) }\end{array}$} & $\begin{array}{c}\text { Value } \\
(\%)\end{array}$ & \multicolumn{2}{|c|}{$\begin{array}{l}\text { 95\% Confidence } \\
\text { Interval (\%) }\end{array}$} & $\begin{array}{c}\text { Value } \\
(\%)\end{array}$ & \multicolumn{2}{|c|}{$\begin{array}{l}\text { 95\% Confidence } \\
\text { Interval (\%) }\end{array}$} \\
\hline & & Lower & Upper & & Lower & Upper & & Lower & Upper \\
\hline Sensitivity & 100 & 77.1 & 100 & 100 & 77.1 & 100 & $94 \cdot 1$ & 69.2 & $99 \cdot 7$ \\
\hline Specificity & 93.8 & $67 \cdot 7$ & 99.7 & 87.5 & $60 \cdot 4$ & $97 \cdot 8$ & $87 \cdot 5$ & 60.4 & 97.8 \\
\hline PPV & 94.4 & 70.6 & 99.7 & 89.5 & $65 \cdot 5$ & 98.2 & 88.9 & 63.9 & 98.1 \\
\hline $\begin{array}{l}\text { NPV } \\
\text { Accuracy }\end{array}$ & $\begin{array}{c}100 \\
97\end{array}$ & $74 \cdot 7$ & 100 & $\begin{array}{r}100 \\
93.9\end{array}$ & $73 \cdot 2$ & 100 & $\begin{array}{l}93 \cdot 3 \\
90.9\end{array}$ & $66 \cdot 0$ & 99.7 \\
\hline \multirow[t]{12}{*}{ B. } & & & & \multicolumn{3}{|c|}{ IVDPCT in theatre } & \multicolumn{3}{|c|}{ Frozen section } \\
\hline & & & & CA & Non-CA & Total & CA & Non-CA & Total \\
\hline & & & Test + & 4 & 2 & 6 & 4 & 3 & 7 \\
\hline & & & Test - & 0 & 20 & 20 & 0 & 18 & 18 \\
\hline & & & Total & 4 & 22 & 26 & 4 & 21 & $25^{\star \star}$ \\
\hline & & & & $\begin{array}{c}\text { Value } \\
(\%)\end{array}$ & \multicolumn{2}{|c|}{$\begin{array}{l}\text { 95\% Confidence } \\
\text { Interval (\%) }\end{array}$} & $\begin{array}{c}\text { Value } \\
(\%)\end{array}$ & \multicolumn{2}{|c|}{$\begin{array}{c}\text { 95\% Confidence } \\
\text { Interval (\%) }\end{array}$} \\
\hline & & & & & Lower & Upper & & Lower & Úpper \\
\hline & & & Sensitivity & $100 \cdot 0$ & $39 \cdot 6$ & $100 \cdot 0$ & $100 \cdot 0$ & 39.6 & $100 \cdot 0$ \\
\hline & & & Specificity & 90.9 & $69 \cdot 4$ & 98.4 & $85 \cdot 7$ & $62 \cdot 6$ & $96 \cdot 2$ \\
\hline & & & PPV & $66 \cdot 7$ & 24.1 & 94.0 & $57 \cdot 1$ & $20 \cdot 2$ & 88.2 \\
\hline & & & NPV & $100 \cdot 0$ & $80 \cdot 0$ & $100 \cdot 0$ & $100 \cdot 0$ & $78 \cdot 1$ & $100 \cdot 0$ \\
\hline & & & Accuracy & $92 \cdot 3$ & & & 88.0 & & \\
\hline
\end{tabular}

*Haptoglobin at cut-off $2.85 \mathrm{mg} / \mathrm{ml}$; ${ }^{* *}$ Haptoglobin at cut-off $0.5 \mathrm{mg} / \mathrm{ml}$; PPV - positive predictive value; NPV - negative predictive value; IVDPCT - in vitro diagnostic point-of-care test device.

${ }^{* *}$ One FS did not provide a diagnosis due to technical difficulties during cryosectioning whereas IVDPCT and histology results were concordant.

This article is protected by copyright. All rights reserved. 
Table 3 Sensitivity, specificity, PPV and NPV of cyst fluid haptoglobin determined by RCA and IVDPCT in the differential diagnosis of benign and malignant epithelial ovarian tumours in $\mathbf{1 5 0}$ blinded samples (clinical assay development phase $(n=50)$ and prospective validation phase $(n=100))$.

\begin{tabular}{|c|c|c|c|c|c|c|c|c|c|}
\hline & \multicolumn{3}{|c|}{$\operatorname{RCA}(n=50)$} & \multicolumn{3}{|c|}{ IVDPCT in lab $(n=50)$} & \multicolumn{3}{|c|}{ IVDPCT in theatre $(n=50)$} \\
\hline & CA & Non-CA & Total & CA & Non-CA & Total & CA & Non-CA & Total \\
\hline Test + & 18 & 3 & 21 & 19 & 1 & 20 & 7 & 6 & 13 \\
\hline Test - & 3 & 26 & 29 & 0 & 30 & 30 & 3 & 34 & 37 \\
\hline \multirow[t]{3}{*}{ Total } & 21 & 29 & 50 & 19 & 31 & 50 & 10 & 40 & 50 \\
\hline & $\begin{array}{l}\text { Value } \\
(\%)\end{array}$ & \multicolumn{2}{|c|}{$\begin{array}{l}95 \% \text { Confidence } \\
\text { Interval (\%) }\end{array}$} & $\begin{array}{l}\text { Value } \\
\text { (\%) }\end{array}$ & \multicolumn{2}{|c|}{$\begin{array}{l}\text { 95\% Confidence } \\
\text { Interval (\%) }\end{array}$} & $\begin{array}{l}\text { Value } \\
(\%)\end{array}$ & \multicolumn{2}{|c|}{$\begin{array}{l}\text { 95\% Confidence } \\
\text { Interval (\%) }\end{array}$} \\
\hline & & Lower & Upper & & Lower & Upper & & Lower & Upper \\
\hline Prevalence & $42 \cdot 0 \%$ & & & $38.0 \%$ & & & $20 \cdot 0 \%$ & & \\
\hline Sensitivity & $85 \cdot 7 \%$ & $62 \cdot 6 \%$ & $96 \cdot 2 \%$ & $100 \cdot 0 \%$ & $79 \cdot 1 \%$ & $100 \cdot 0 \%$ & $70 \cdot 0 \%$ & $35.4 \%$ & $91.9 \%$ \\
\hline Specificity & $89.7 \%$ & $71.5 \%$ & $97 \cdot 3 \%$ & $96 \cdot 8 \%$ & $81.5 \%$ & $99 \cdot 8 \%$ & $85.0 \%$ & $69 \cdot 5 \%$ & $93.8 \%$ \\
\hline PPV & $85.7 \%$ & $62.6 \%$ & $96 \cdot 2 \%$ & $95.0 \%$ & $73 \cdot 1 \%$ & $99 \cdot 7 \%$ & $53 \cdot 8 \%$ & $26 \cdot 1 \%$ & $79.6 \%$ \\
\hline NPV & $89.7 \%$ & $71.5 \%$ & $97 \cdot 3 \%$ & $100 \cdot 0 \%$ & $85.9 \%$ & $100 \cdot 0 \%$ & $91.9 \%$ & $77 \cdot 0 \%$ & $97.9 \%$ \\
\hline Accuracy & $88.0 \%$ & & & $98.0 \%$ & & & $82.0 \%$ & & \\
\hline
\end{tabular}

Haptoglobin at cut-off $0.5 \mathrm{mg} / \mathrm{ml}$; RCA-rapid colorimetric assay; IVDPCT-in vitro diagnostic point-of-care test device; CA-Cancer; Non-CA Non-Cancer; PPV-positive predictive value; NPV-negative predictive value 
Figure 1.

$1 \mathrm{~A}$

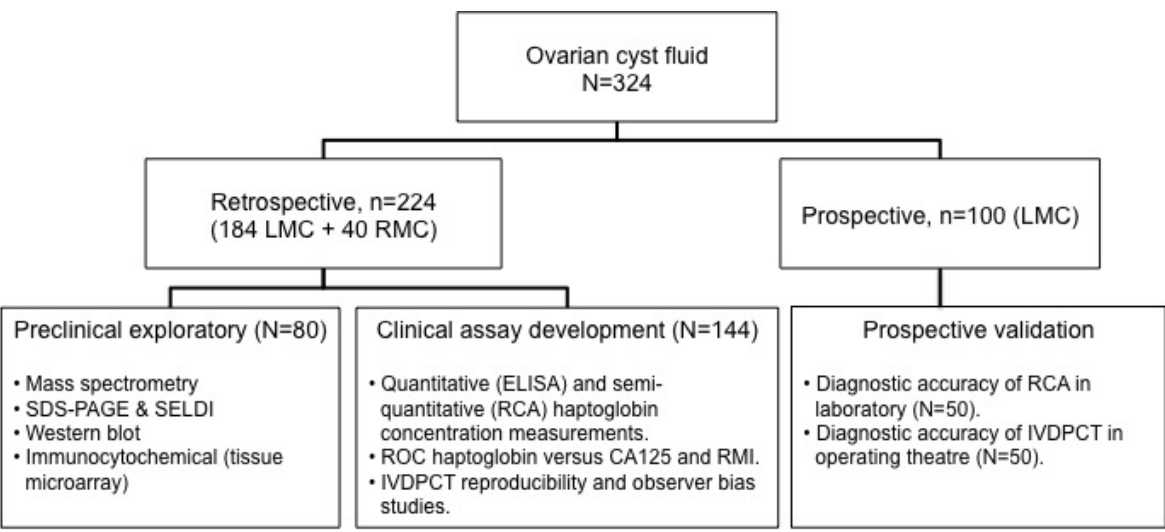

SDS-PAGE-sodium dodecyl sulfate-polyacrylamide gel electrophoresis; SELDI-surface-enhanced laser desorption/ionization; LMC-local medical centre; RMC-regional medical centres; ELISA-enzyme-linked immunosorbent assay; RCA-rapid colorimetric assay; ROC-receiver operating characteristics; RMI-risk of malignancy index; IVDPCT-in vitro diagnostic point-of-care test

1B

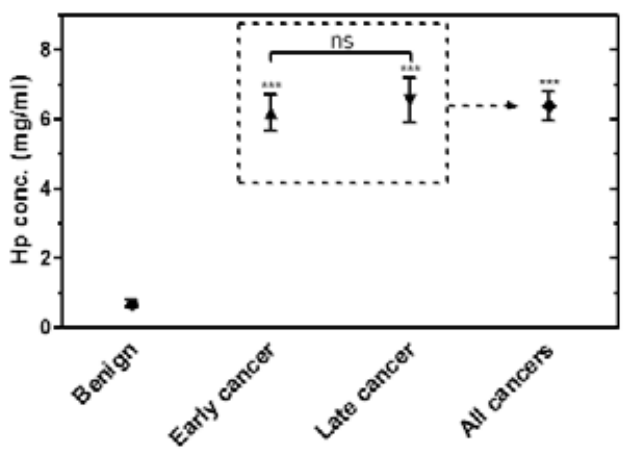

$1 \mathrm{C}$

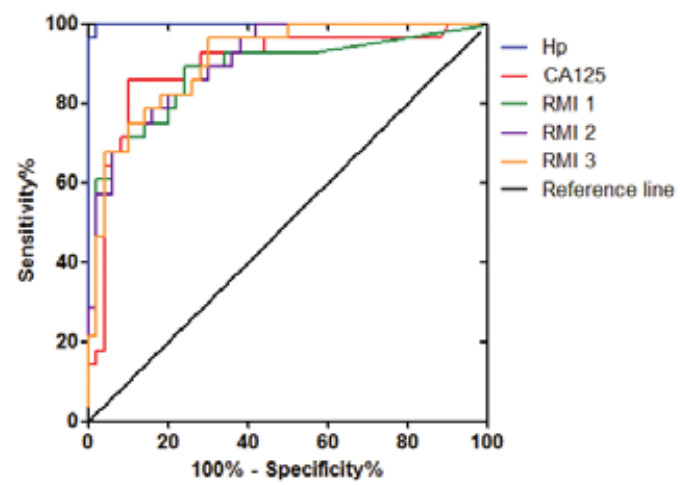

Figure 1 Haptoglobin levels are increased in ovarian cancer cyst fluid (CF). (A) Distribution and use of retrospective and prospective OCF samples for preclinical exploratory, clinical assay development and prospective validation study. (B) ELISA for ovarian cyst fluid (OCF) haptoglobin in 87 benign ovarian tumours, 17 early and 20 late stage ovarian cancers. Data are mean \pm S.E.M. ${ }^{* * *} P<0.0001$ versus benign. ns=non-significance $(P=0.98)$. (C) ROC curve analysis showing the relationship between sensitivity and specificity for CF haptoglobin (blue line), serum CA125 (red line), RMI 1 (green line), RMI 2 (purple line) and RMI 3 (orange line) in the discrimination between benign tumours ( $n=50$; six benign cases without serum CA125 information were excluded from ROC analysis) and ovarian cancers $(n=28)$. Haptoglobin performed better than CA125 $(P=0.013), \mathrm{RMI} 1$ (AUC 0.879, 95\% Cl 0.793-0.966; $P=0.007$ ), RMI 2 (AUC 0.906; 95\% Cl 0.843-0.970; $P=0.005$ ) and RMI 3 (AUC 0.909, 95\% Cl 0.846-0.973; $P=0.006$ ). At a haptoglobin cut-off level of $2.85 \mathrm{mg} / \mathrm{ml}$ the sensitivity was $97 \cdot 3 \%$ (95\% Cl 84·2-99.9\%), specificity was 97.7\% (95\% Cl 91-1-99.6\%), PPV was 94.7\% (95\% Cl $80 \cdot 9-99 \cdot 1 \%)$ and NPV was $98 \cdot 8 \%$ (95\% Cl 92.8-99.9\%), at a prevalence of 3:2 benign to malignant cases.

This article is protected by copyright. All rights reserved. 